\title{
APPLICATION OF PARTICLE MOTION TECHNIQUE TO STRUCTURAL MODAL IDENTIFICATION OF HERITAGE BUILDINGS
}

\author{
Oriol Caselles ${ }^{1}$, Guillermo Martínez ${ }^{2}$, Jaume Clapes ${ }^{3}$, Pere Roca ${ }^{4}$ and Vega Pérez Gracia ${ }^{5}$ \\ 1 Technical University of Catalunya, Department of Geotechnical Engineering and Geosciencies of the UPC, C. Jordi Girona, \\ 1-3, Barcelona, Spain, 08034. (34) 93 4017257, oriol.caselles@upc.edu. \\ 2 \\ 2 Universidad Michoacana de San Nicolás de Hidalgo, Av. Francisco J. Mujica S/N, Edificio de Posgrado de Ingeniería Civil, \\ Morelia, Michoacán, México, 58010. (52) 443 3041002, gmruiz@umich.mx. \\ 3 Technical University of Catalunya, Department of Geotechnical Engineering and Geosciencies of the UPC, C. Jordi Girona, \\ 1-3, Barcelona, Spain, 08034. (34) 93 4016874, jaime.clapes@upc.edu. \\ 4 \\ 4 Technical University of Catalunya, Department of construction engineering of the UPC, C. Jordi Girona, 1-3, Barcelona, \\ Spain, 08034. (34) 93 4017381, pere.roca.fabregat@upc.edu. \\ 5 Technical University of Catalunya, Department of strength of materials and structural engineering, Comte D'urgell 187, \\ Barcelona, Spain, 08036. (34) 93 4137333, vega.perez@upc.edu.
}

Determining the behaviour of a structure estimated by means of finite elements analysis requires, not only an in depth knowledge of its geometry and dynamic properties, but also an experimental validation to corroborate the adequacy of the characteristics of the structure. Most of the current structural identification techniques are based on linear methods that call for a lot of measurement points and/or a relative simple structure. Complex structures are somewhat still an unexplored field due to the difficulties with the finite element method and the experimental corroboration of its results. In this work we present the use of particle motion computation applied to each structural vibration mode to improve the identification of its dynamic properties, and its application to the Gothic Cathedral of Palma de Mallorca (Spain).

\section{INTRODUCTION}

The increasing computing power of PCs has led to the generalisation of exhaustive studies of engineering structures by means of finite element calculations, and thus to the existence in the market of a great amount of computer programs. Uncertainties associated with the dynamic characteristics and inner geometry of the actual constructions lead to the development of numerous methodologies to correctly estimate these aspects and their application to finite element methods (Liu et al., 2005; Ljung, 1999). Due to this improvement, there has been an effort to apply all this knowledge to especially relevant structures, such as very ancient monuments. Nevertheless, two main difficulties arise: on the one hand, their dimensions and structural complexity, and on the other hand, the lack of information on the dynamic behaviour of the elements, especially if they show the characteristic deterioration of such structures. 
Taking all these aspects into account, several studies on the linear and non-linear dynamic behaviour of ancient structures by means of finite element methods have seen the light. Most of these simulations were not based on in situ measurements (Ramos and Lourenço, 2004; Arias et al., 2007), while others used the periods already measured (Lourenço et al., 2007; Carusi et al., 2005). Only a few structures were studied by more precise output only dynamic techniques as experimental modal analysis (Erdogmus and Boothby, 2005; Bayraktar et al., 2008; Bayraltar et al., 2009; Ramos et al., 2010), and they were comparatively simpler or just a section of the structure. The reason: the technique in very complex structures was very complicated and the economic and human cost excessive. The relatively simple structures frequently show little interaction between bending modes (longitudinal and transversal) and torsional modes. Therefore, the identification of modes is perfectly feasible by comparing the modes measured in two or more conveniently chosen points of the structure. This does not occur in complex and asymmetrical structures, such as cathedrals and other monuments. In this type of constructions, the structural elements causing the mode asymmetry lead to the existence of vibration modes that are not purely flexional or torsional, but that mix the three movements. The great efforts that need an experimental modal analysis in large and complex structures recommend a good knowledge of its dynamic behaviour and possible modal shapes to optimize the sensor location and assure a good coverage of the important places to determine the real modal shapes. For ancient structures were dynamic properties uncertainty is great and the probably modal shapes could be complex seems a good idea to compute a preliminary numerical model experimentally corroborated. In this work we present the use of particle motion computation applied to each structural vibration mode to corroborate the identification of its dynamic properties, and its application to the Gothic Cathedral of Palma de Mallorca (Spain). This easy and low cost experimental technique allows us to know the frequency modes and how is the modal shape in the measured points.

\section{THE CATHEDRAL OF MALLORCA}

St. Mary's basilica in Palma de Mallorca is one of the greatest examples of the so-called Catalan Gothic. Its construction of this cathedral started in the beginning of the 14th century and it was concluded in 1601. It was built where the old Mosque of Madina Mayûrqa used to be located (Domenge, 1995). The main characteristic of this type of gothic is its structure: three naves with similar height and separated by slender columns, which transform the inside into a great unique space. Slender columns need light vaults and roofs and, at the same time, load as much of its own weight as possible to the buttresses. So, for this cathedral it was necessary to build a large amount of buttresses and lateral naves of similar height of the main one. An effect of this design is a decreasing of the inner luminosity; opposite to the European Gothic that was built to increase it. The similarity of the height of the three naves made the flying arches unnecessary. Mallorca's cathedral, which is the Bishopric seat, is an atypical case of Mediterranean Gothic.

On the one hand, it maintains the concept of a unique space with thin columns, but the main nave has a height, with regard to the aisles, that is between Gothic and European Gothic styles. In this case the ratio between the height of the main nave and lateral naves is 1.5, while in French churches it is greater than 2 (in Reims is 2.27) (Salas, 2002) and 1.14 at Santa Maria del Mar in Barcelona. Another difference between Mallorca Cathedral and Catalan Gothic Style is the use of double flying arches to unload the weight of the main nave vaults and the roof cover. Indeed, using them incorrectly (Mark, 1982), probably due to inexperience, is the main cause of the structural problems this cathedral has undergone for the past years. This supposed mixture of gothic styles has led some authors to envisage the possibility that the unknown architect of Mallorca's cathedral were French. Nevertheless, the most logical explanation seems to come from the changes in the design that occurred during the first half of the 14th century, when a nearby and higher church was built. Then, the cathedral was redesigned and the original one-nave structure gave place to a three-nave structure and an increase in height from $29 \mathrm{~m}$ to $44 \mathrm{~m}$. In order to reuse the already built altar, chapels and apses, the aisles had to be similar in height to the main nave. This justifies 
the abnormal height of the naves (Figure 1) and the side chapels, which is similar to the side apses'. To solve the problem of the side cover loads of the main nave, double flying arches, characteristic of the European Gothic style, were chosen rather than extending the buttresses. On the other hand, to unload the weight of the aisles, the buttresses were extended (typical solution of the Mediterranean Gothic style). The inexperience of the architects that designed this extension is reflected in the fact that the upper flying arch, instead of taking care of the side loads of the main nave, causes its closure. Thus, since it was built, the arch keys had to be overloaded with dead weights and in some cases supported over the lower flying arch (Figures 2 and 3) (Domenge, 1995). Mallorca's cathedral is a three-nave church, $77 \mathrm{~m}$ long and with a $35 \mathrm{~m}$ apse and a trinity chapel located at the east side. Thus the total length of the building is of $121 \mathrm{~m}$. The main nave vault is a double square quadripartite vault $18.7 \mathrm{~m}$ wide and $43.95 \mathrm{~m}$ high, while the aisles are simple square quadripartite vaults, $9.4 \mathrm{~m}$ high and $8.75 \mathrm{~m}$ wide. The main apse vault is $27 \mathrm{~m}$ high, while the side apse vaults are $19 \mathrm{~m}$ high (Figure 4). The naves consist in 8 sections or centrelines, 7 of which are $9.3 \mathrm{~m}$ long and an $11.9 \mathrm{~m}$ false transept. The piles cross section supporting the main nave are octagonal (each side is 61 to $69 \mathrm{~cm}$ ) and have a height of $22.7 \mathrm{~m}$, which is one of the greatest ratios height/column width (Table 1). The first three pairs of columns from the apse are the oldest and have $61 \mathrm{~cm}$ column width, while the four pairs located in the west part are more recent (16th century) and wider (column width: $69 \mathrm{~cm}$ ). The difference in heights among naves translates into a wide clerestory, with one of the greatest rose windows of the Gothic style (11.5 m in diameter), built in 1370. Its design draws a David's star and it is located over the presbytery, instead of its usual place, the main door. Right by the northern wall of the cathedral and in a $10^{\circ}$ angle there is a $48 \mathrm{~m}$ bell tower and a cloister. Some authors (García-Delgado, 2000) think that this inclination is due to the fact that these two elements profited from the design of the streets of the old Roman city.

The cathedral, on the other hand, is oriented to Mecca, as it was built on the foundations of the ancient mosque of "Madîna Mayûrqa". The bell tower is only in contact with the cathedral by the side chapels, and it separates a few centimetres from the aisle. The bell tower, the wider buttresses of the south and north doors, the façade, the apse and the difference in width of the columns play a significant role in the behaviour of the structure, as they translate into an asymmetry of the stiffness, which in its turn leads to complex vibration modes. The cathedral has endured, over the years, significant structural damage, due to its design. The first important repair took place in 1639 (Jovellanos, 1832) and from then on the maintenance works have been frequent. Nowadays the cathedral presents relatively important cracks in many of its elements. The acute thermal differences between Mallorca's summer and winter (from $-2^{\circ} \mathrm{C}$ to $40^{\circ} \mathrm{C}$ ) play an essential role in cracks behaviour. A study on the weather changes of natural frequencies throughout the year showed an approximate variation of $10 \%$ (Elyamani et al., 2012). Clearly this indicates the significance of the changes in stiffness caused by the expansion and contraction of the masonry, and thus of its cracks.

\section{PARTICLE MOTION TO IDENTIFY MODAL SHAPES}

The 3D representation of particle motion is typically used in seismology to identify and study seismic phases (Aki and Richards, 1980; Tobita and Sawada, 2006). This method, in general terms, identifies the shape and amplitude of the movement at significant seismic phases by a sensor fixed at a specific point. The application of this method is also common when taking a tomography of the crustal structure of the Earth (Mitchell, 1976; Caselles et al., 1997). In seismology, due to the interest in studying the changes of spectral amplitude in time, the standard multiple filtering analysis is used to separate the significant phases from the rest of the seismogram (Herrmann, 1973). But in great complex structures, with ambient noise as the source of excitation, this filtering proves to be inadequate. In order to identify the structure's mode shapes at the measured points, the first step consists in identifying the vibration mode frequencies by means of the recorded power spectrum peaks (Figure 5). Then the records are filtered separating the different modes estimated (Figure 6). At this point, although most casual filters do, it is important to use filters that do not ripple or disturb the phase (Buttkus, 2000). To minimize 
these effects a Butterworth band pass filter would be preferable. This is a time domain filter that fulfils the above-needs and, by using a different order number, allows somehow a brisk cut depending on the needs of the signal (Butterworth, 1930; Jackson, 1986). Once the time signal for the vibration mode is obtained, the projections of the 3D measured points trajectories are drawn. This allows analysing the shape of the mode at a given point or comparing it to other points, which can also be measured simultaneously or not. If the vibration mode frequencies are very close, it is important to check the power spectral density to assure that the filtered signal is not contaminated by near mode energy due to a poorly selective filter. When a peak in the power spectral density appears in one or more channels, it is important to assure if both correspond to a mixed modal shape or if they are caused by two independent modes. To distinguish between both possibilities, the best way is to compute and draw coherence function between both channels. A high coherence between channels at the modal frequency indicates the existence of an only one mode with displacement in both directions. Low coherence between channels at the modal frequency is more probably related with the existence of two independent modes. If more than one point is simultaneously measured it is desirable to observe the phases of both cross spectra, as it facilitates determining if they are in phase or opposite, if they form a particular angle or if the experimental frequency does not correspond to a pure mode, but rather to two modes whose frequency is experimentally undistinguishable.

\section{FINITE ELEMENT MODEL}

The current numerical model is a significant first step towards the understanding of the structural behaviour of the cathedral. The present analysis is about the structural behaviour regardless of the existing crack pattern. The geometrical information needed to develop the finite element model was obtained from (Casarin and Magagna, 2001) and (González and Roca, 2000). Each of the macroelements into which the cathedral can be divided was independently built in order to enable their partial and global study. Each macroelement is formed of different types of elements with regard to their needs. Thus, 463768 tetrahedral solid elements and 28473 triangular shell elements were used (Figure 7). According to historical information and visual site observations, we divided all the building materials in three main types. The first one is the used in vaults, walls and buttresses. A second material, more resistant than the first one, is the used in columns and flying arches, and the third material is for the infill material used to fill the vault voids. The initial values of the deformation modulus were established regarding the experimental and compression tests performed on stones from different zones of the structure (González and Roca, 2003). In the Table 2 another mechanical values are resumed and according to Eurocode 6 (EC- 6, 2005) and the masonry structures recommendations (PIET 70, 1971), the used compressive strength was equal to 1/1000 times de Young Modulus, the tensile strength was equal to $5 \%$ of the compressive strength, and an average masonry 0.2 Poisson Modulus was used. The used density values were obtained from previous studies (González and Roca, 2003) performed over the structure. The pinacles and dead weights from the mean vault were substituted by concentrated masses. The eigenvalues analysis was carried out by means of DIANA Program (TNO DIANA, 2012). From the eigenvalue analysis, and by updating the initial stiffness, a correct adjustment of the frequencies measured by this study was performed, as the analysis does not take into account the cracks or the likely effects of an interaction between the soil and the structure. The model calibration was performed varying the Young Modulus (Table 2) using the square of the ratio of the periods according to the Equation (1), were $m$ and $K$ are the mass and stiffness of the structure respectively, and only matching the frequency associated to the first mode of vibration (Table 3). The used density values were obtained from previous studies (Roca, 2004) performed over the structure.

$$
T=2 \pi \sqrt{\frac{m}{k}}
$$


The final stiffness, which represents a 50\% variation from the original values, is shown in Table 2 . The adjusted frequencies undergo minor changes (8\%), with respect to the measured values.

\section{PARTICLE MOTION TO IDENTIFY MODAL SHAPES IN MALLORCA CATHEDRAL}

This study is included within a project to evaluate the structural conditions and behaviour of Mallorca's cathedral. During this global project many historical, structural and geophysical studies were developed (Pérez-Gracia et al., 2009). One of the aims of the project was to build a detailed and reliable numerical model capable to represent adequately the linear and non-linear dynamic behaviour of the structure. According to the International Scientific Committee on the Analysis and Restoration of Structures of Architectural Heritage (ICOMOS/ISCARSAH, 2003) of the International Council of Monuments and Sites, it is very important to get physical information in order to minimize the uncertainties present in heritage buildings. In order to do so, the best way to measure the dynamics of this structure, characterised by its great dimensions, complexity and level changes, was proposed taking into account the resources available. The first phase consists in taking non-simultaneous triaxial measures at points of the structure that, because of their location, may provide more information. Then, the numerical model is refined by means of a second phase that allows simultaneous triaxial and biaxial measures in more than one point, which will better corroborate the modal shapes of the model.

One of the disadvantages of the studied structure is the frequency range. On the one hand, a structure of these characteristics has low natural frequencies, which requires long measuring periods and low-frequency sensors and acquisition data systems. On the other hand, it is desirable to measure the natural frequencies of the elements making up the structure (for example, the vaults in Mallorca Cathedral has a natural frequency around $40 \mathrm{~Hz}$ with about 500 times more spectral amplitude velocity than the structural modes, Figure 8). A good determination of the dynamic properties of these elements allows a better knowledge of the whole structure. That is why a $136 \mathrm{~dB}$ system with a plane frequency response ranging from 0.05 to $40 \mathrm{~Hz}$ was used. The system allows us to measure suitable and with enough resolution an adequate spectral range computing spectra in real time. Computing spectra in real time has the advantage of finish the acquisition time when the spectrum becomes stable. In our case, we measure in a windy day that probably permits short acquisition times. The measuring times were from 120 to 200 seconds depending of the measuring point. This measuring window length assures a minimum of 10 overlapped Hanning windows of 30 seconds (with a frequency resolution of about $0.03 \mathrm{~Hz}$ ). Another disadvantage of this structure is the lack of horizontality of the main nave roof, which is partially covered by a false void ceiling that, in modern ages, was covered by a light roof made of metal, wood and clay tiles. This facts limited the installation of the sensor over the main nave to the arches due to the extrados of the nave is not accessible (Figure 3). In order to measure the longitudinal behaviour of the main nave, 5 measurements on the roof were taken: 2 on the back arches (measurements A4 and A5 in Figure 4), 2 on the front arches (A6 and A7 in Figure 4) and 1 on the façade (A8 in Figure 4). Thus, it is easy to observe the response of the nave to bending when the structural elements that cause its asymmetry are present. To measure the transversal behaviour of the cathedral, different pairs of non- simultaneous measurements were taken in both aisles (measurements 6 and 9, 2 and 8, 3 and 7 in Figure 4) together with the corresponding measurements in the main nave (measurements A5, A6 and A7, respectively) and the pair of measurements 4 and 5 (Figure 4) at both ends of the northern nave.

By comparing the modal shape of the structure at these points, an approximate idea of these shapes and some strong restrictions the numerical model should fulfil are obtained. Likewise, this simple and fast application allows designing future measuring campaigns. In the case of Mallorca's cathedral, this fact is especially significant due mainly to the structural asymmetries above-mentioned and to the complexity of the structure. In order to use the particle motion to identify modal shapes, the time signal should be filtered to isolate the movement caused by 
the response of each structural mode. In the case of Mallorca's cathedral the vibration mode frequencies are quite similar (1.28, 1.47, 1.59, 1.84 and $2.03 \mathrm{~Hz}$ for the first 5 modes, Figure 5) and have very different spectral amplitude that tends to change regarding the measuring point. This fact led to the use of an 8-point Butterworth filter. In the present research we used a reduced number of sensor positions, which allow a good identification and matching of the first modal frequencies, but are not adequate for a reasonable high modal matching. Once the signals are filtered, the filtered spectra are plotted to ensure that, despite the filter, no contamination takes place among the energies of neighbouring modes (Figure 6). These measures ensure the adequacy of the observations and conclusions obtained. When aligning sensors A4 and A8, note that the three first modes are clearly flexions in the longitudinal direction in the sensor placed at the façade (point A8), while, due to the above-mentioned asymmetry, they show complex or transversal shapes in points A4 and A5 (Figure 9). This figure clearly shows how the great stiffness of the façade generates complex modal shapes. The first mode, undoubtedly transversal in the apse area, becomes longitudinal in the façade. The observation of the vertical-transversal projection (Figure 10) leads to conclude that the movement in the façade is purely longitudinal as it lacks vertical component; while in the apse, the strong vertical component, coupled with the $\mathrm{N}$ - S component, obviously indicates that the arches endure some compression and swelling. The second mode, which is mainly longitudinal and somewhat complex in the apse area, also becomes purely longitudinal in the front. As in the first mode, the vertical projections indicate, to a lesser extent, the coupled closing and opening of the arches in the apse area. The third mode, which in the apse area forms a $28^{\circ}$ angle with the north, becomes purely longitudinal. This mode also shows the closing-opening of the arches in the apse area. The fourth mode is clearly transversal in the apse area and also becomes longitudinal in the façade. Finally, mode 5 is both longitudinal and transversal in all arches, while only longitudinal in the façade. As for the experiments developed to observe the transformation of the modal shape in the transversal axis, the asymmetry

mainly stands out in the third and fourth modes (Figure 11). Points 6 and 9 at the edge of the main nave columns do not show any vertical movements. The first mode of the aisles is basically longitudinal, slightly to the NE at Point 6 (approx. $12^{\circ}$ ) and to the SE at Point 9 (approx. $9^{\circ}$ ). Should these two components N-S is in phase, the above-mentioned closing- opening of the arches would be justified. Whilst should they be opposed, a rotation would occur without an opening of the main nave arches. In spite of this simplification of the shape of the first mode, it is not easy to justify the NW $25^{\circ}$ orientation observed at Point A5. A possible explanation would be the existence of an undetected asymmetric element in the main nave cover that had no special relevance on the modal shape globally, but locally. Another element that could distort the symmetry of the different arches of the main nave could be the presence of supports in just some of the upper flying arches (Figure 3). Finally, the distortion of the movement in this mode at the mentioned point could also be explained by the existing crack pattern or the slight bend of some columns. In the second mode the obvious E-W direction $\left(90^{\circ} \mathrm{N}\right)$ observed at Point 6 become $75^{\circ} \mathrm{NE}$ at Point 9 and $83^{\circ}$ at Point A5. It becomes clear that the south aisle shows less longitudinal stiffness for this mode, which leads to a coupling between longitudinal flexion and rotation centred on the northern aisle. This stronger stiffness can be attributed to the presence of a bell tower. The third mode shows a more complex shape: the transversal-vertical character of Point A5 and the almost horizontal but longitudinaltransversal movements of the roof of the two aisles (Points 6 and 9). The fourth mode seems to present a movement opposed to the second one. The clear transversal direction $\left(0^{\circ} \mathrm{N}\right)$ of Points 6 and A5 becomes $75^{\circ} \mathrm{NE}$ at Point 9 with opening-closing of the arches. As in the points located throughout the main nave, the fifth mode presents a complex shape at these points.

\section{COMPARISON BETWEEN NUMERICAL MODEL AND EXPERIMENTAL OBSERVATIONS}

As stated before it is almost impossible to carry out the correct experimental modal calculation of such a great and complex structure. This complexity is what makes these numerical models unreliable when they are used in delicate fields such as restoration and dynamic behaviour in front of earthquakes and wind. On the other hand, given the obvious resemblance between the numerical model and the real structure, the study of the theoretical 
behaviour of the former allows designing more adequately new measuring campaigns in the most relevant areas either because they show special movements (for instance: vibration nodes, accelerations and maximum stresses) or because they are points of special interest.

Another important factor for the numerical and experimental model comparison is the existence of cracks in important structural elements and the connections between them. Given that the numerical simulation does not contemplate this fact yet, measurements were carried out during the summer season, when the cracks were less evident and thus their real behaviour resembled that of the non fissured one. Therefore, it is impossible for the model to adjust perfectly to experimental data. In order to compare the modal shape calculated numerically and the particle movement measured experimentally in 19 locations of the cathedral, the experimental points were firstly marked in the mesh of the numerical model. Then, the structure was animated in each of the first five vibration modes, the movement images were captured (Figure 12), and the particle movements digitalised at each point and for each vibration mode. Finally, the numerical movement was normalised and plotted jointly with the experimental displacements. The first main result of the comparison between experimental and numerical analysis is the numerical facade stiffness in transversal direction is enough to assure that all the modes at this point are mainly transversal, probably little greater than the reality because in experimental data exist a little acceleration in North-South direction without correspondence with numerical values (Figure 13). Also, in facade, numerical values predict a little component in vertical direction reflecting a bending mode not perfectly corresponding with numerical data. Probably the effect of the rose-window main façade is not perfectly simulated in numerical model but enough for our proposal.

The first mode is the best adjusted one in all the point, probably reflecting this has the simplest shape. The change in the direction of the first mode from longitudinal to $45^{\circ}$ is mainly well defined in the numerical model. the second mode has also a good correspondence between numerical and experimental data. This mode is mainly longitudinal on the roof of the main nave in both but experimentally the eccentricity of the elliptical movement is greater than in numerical.

In general, the thirds, fourth and five modes are transversal in the main nave changing suddenly to longitudinal in façade but the low eccentricity of the thirds and five mode is not well adjusted in numerical modes (Figure 14).

\section{CONCLUSIONS}

The particle movement graphics at a point of a structure and the comparison among movements at different points is a powerful and adequate tool for a first numerical model validation better than model frequency validation at a relative low increase of cost. Also, this technique can be used as a first step to optimize sensor location in experimental modal analysis due to allow us to know where the modes have higher vibration levels and where have minimum or are not detected. Moreover, the comparison between particle movements and the numerical model on the adequate positions of a structure can point out the importance of some structural elements of complex structures. In the case of Mallorca's Cathedral, the asymmetry observed among the movements of the aisles led to the introduction of the bell tower in the Cathedral model.

It should be taken into account that the bell tower is only attached to the rest of the structure up to the level of the side chapels and thus its main role in the modal shapes is not obvious. Moreover, in this case, the shapes of the first vibration mode in Points 6, A5 and 9 are not completely explained by the numerical model. This lead to think that further research should be 
carried out on how the ceilings, the light cover and the dead-weight over the arches of the main nave were constructed and on the role of the supports of the upper flying arches and existing cracks. Especially at Point A5 where a certain asymmetry occur, which in turn generate a local distortion of the shape of that mode. The discrepancy between reality and simulation can be of great significance when these numerical models are used to simulate the dynamic behaviour in front of earthquakes or to propose reinforcements or repairs. In general, the adjustment of the numerical model for this case is very accurate due to the existing time variability. A future numerical model taking into account the existing cracking should include measures under different thermal conditions to corroborate the changes of the modal shapes predicted by this model.

Finally, the observation of the movement generated by the numerical simulation makes it interesting to simultaneously measure the different arches of the main nave in order to know the closing degree of the arches longitudinally; the simultaneously measurement in the NS edges and at the centre of each arch of the main nave, in order to know the closing degree of the arches transversally, and the measurement in the upper part of the pillars, flying arches and the rest of the points where there is a maximum displacement or stress in the model.

\section{AKNOWLEDGMENTS}

The research described in this article is part of the activities of the EU-India Economic Cross Cultural Programme “Improving the Seismic Resistance of Cultural Heritage Buildings”, Contract ALA-95-23-2003-077-122.

\section{REFERENCES}

Abruzzese, D., Vari, A. 2005. Seismic resistance of masonry towers. In: Laurenço et al. editors. Structural Analysis of Historical Constructions, 1:451-60.

Aki, K., Richards, P.G. 1980. Quantitative seismology. W.H. Freeman and company.

Antonacci, E., Beolchini, G.C. 2005. The dynamic behaviour of the façade of the Basílica S. Maria di Collemaggio. In: Laurenço et al. editors. Structural Analysis of Historical Constructions, 1:469-76.

Arias, P., Armesto, J., Di-Capua, D., González-Drigo, R., Lorenzo, H., Pérez-Gracia, V. 2007. Digital photogrammetry, GPR and computational analysis of structural damages in a medieval bridge. Eng. Failure Analysis, 14:1444-57.

Baptista, M.A., Mendes, P., Afilhado, A., Agostinho, L., Lagomarsino, S. 2005. Mendes Victor L. Ambient vibration testing at N. Sra. Do Carmo Church, preliminary results. In: Laurenço et al. editors. Structural Analysis of Historical Constructions, 1:483-8.

Bayraktar, A., Altunişik, A., Birinci, F., Sevim, B., and Türker, T. 2008. Modal Analysis, Experimental Validation and Calibration of a Historical Masonry Minaret. Journal of testing and evaluation, 36:516-524.

Bayraktar A., Temel Türker, T., Sevım, B., Ahmet Can Altuni,sik, Faruk Yildirim, F., 2009. Modal Parameter Identification of Hagia Sophia Bell-Tower via Ambient Vibration Test. Journal of nondestructive evaluation (Dordretch. Online), 28:37-47.

Butterworth, S. 1930. On the theory of filter amplifier. Wireless Engineer, 7:536-4. 
Çakmak, A.S., Moropoulou, A., Mullen, C.L. 1995. Interdisciplinary study of dynamic behavior and earthquake response of Hagia Sophia. Soil Dynamics and Earthquake Engineering, 14:125- 33.

Carusi, P., Sepe, V., Viskovic, A. 2005. Techniques of structural identification for the monitoring of historical buildings: first experimental results for a masonry tower. In: Laurenço et al. editors. Structural Analysis of Historical Constructions, 1:461-7.

Casarin, F. 2006. Structural Assessment and Seismic Vulnerability of a Complex Historical Building. Ph. D. Dissertation, University of Padova, Milan, Italy.

Casarin, F., Magagna, E. 2001. Analisi strutturale della Catedrale di Palma de Mallorca, Universidad de Padua.

Caselles, J.O., Canas, J.A., Pujades, L., Lana, X., Badal, J., Corchete, V. et al. 1997. Improvements in the knowledge of the anelastic structure of the Iberian Peninsula from seismic data of the ILIHA project. Geophys. J. Int., 129:702-14.

Domenge, J. 1995. L’obra de la Seu. El procés de construcció de la catedral de Mallorca en el trescents, IdEB.

Dooms. D., Degrande, G., De Roeck, G., Reynders, E. 2006. Finite elements modelling of a silo based on experimental modal analysis. Engineering Structures, 28:532-42.

EC-6. Eurocode 6: design of masonry structures - part 1-1: common rules for reinforced and unreinforced masonry structures. 2005. EN 1996-1-1:2005, Brussels.

Elyamani, A., Caselles, J.O., Clapes, J. \& Roca, P. 2012. Assessment of Dynamic Behavior of Mallorca Cathedral. Proceedings of the 8th Internation Conference on Structural Analysis of Historical Constructions. 10 pages, Wroclaw Poland 15-17.

Ellis, B.R. 1998. Non destructive dynamic testing of stone pinnacles of the palace of Westminster. In: Proceeding of the institution of Civil Engineers, Structures and Buildings.

Erdogmus, E., Boothby, T.E. 2005. Validated structural analysis of Gothic vaulted systems. In: Laurenço et al. editors. Structural Analysis of Historical Constructions, 1:421-28.

García-Delgado, C. 2000. Las Raíces de Palma los mil primeros años de la construcción de una ciudad, de la colonia romana a la medina musulmana, Olañeta, DL.

Gentile, C., Saisi, A. 2007. Ambient vibration testing of historic masonry towers for structural identification and damage assessment. Construction and Building Materials, 21:1311-1321.

González, J.L., Roca, P. 2000. Plan de estudios constructivos-estructurales de la catedral de Palma de Mallorca. Universitat Politècnica de Catalunya.

González, J.L., Roca, P. 2003. Estudio del comportamiento constructivo-estructural de la catedral de Santa María, en la ciudad de Palma, isla de Mallorca (Baleares). Part II. Universitat Politècnica de Catalunya.

ICOMOS/ISCARSAH (2003). Recommendations for the analysis, conservation and structural restoration of architectural heritage. Paris (FR). 
Ivorra, S., Palomo, M.J., Verdú, G., Pallarés, F. 2005. A first approach to study an 18th. Century belltower. In: Laurenço et al. editors. Structural Analysis of Historical Constructions, 1:429-37.

Jackson, L.B. 1986. Digital filters and signal processing. Kluwer Academic.

Jovellanos, G.M. 1832. Carta histórico-artística sobre el edificio de la iglesia Catedral de Palma de Mallorca.

Liu, H., Yang, Z. Gaulke, M.S. 2005. Structural identification and finite element modelling of a 14-story office building using recorded data. Engineering Structures, 27:463-73.

Lourenço, P.B., Krakowiak, K.J., Fernandes, F.M., Ramos, L.F. 2007. Failures analysis of Monastery of Jerónimos, Lisbon: How to learn from sophisticated numerical models. Eng. Failure Analysis, 14:280-300.

Mark, R. 1982. Experiments in gothic Structure. The Massachusetts Institute of Technology Press.

Mitchell, B.J. 1976. Anelasticity of the crust and upper mantle beneath the Pacific Ocean from inversion of observed surface wave attenuation. J. Geophys. Res., 81:521- Herrmann, R.B. 1973. Some aspectsof band-pass filtering of surface waves. Bull. Seis. Soc. Am. 63:663-671.

Perez-Gracia, V., Caselles, J.O., Clapes, Martínez, G., J., Canas, J.A. 2009. Integrated near- surface geophysical survey of the Cathedral of Mallorca. Journal of archaeological science, 36:1289-1299.

PIET 70 Obras de fábrica. 1971. Prescripciones del Instituto Eduardo Torroja. Instituto Eduardo Torroja (in Spanish).

Ramos, L.F., Lourenço, P.B. 2004. Modelling and vulnerability of historical city center in seismic areas: a case study in Lisbon. Engineering Structures, 26:295-310.

Ramos, L.F., Marques, L., Lourenço, P.B., De Roeck, G., Campos-Costa, A., Roque, J. 2010. Monitoring historical masonry structures with operational modal analysis. Mechanical Systems and Signal Processing, 24:1291-1305.

Salas, A. 2002. Estudio estructural de los pórticos tipo de la Catedral de Mallorca, Universitat Politècnica de Catalunya.

Shelley, E.O., Ordaz, M., Singh, S.K., Lermo, J. 2000. Estimation of seimic hazard to rehabilitate the temple of La Compañía in Puebla, Mexico. In: Proc. Int. Millenium Congress - Archi. Unesco.

TNO DIANA BV. 2010. DIANA-Finite Element Analysis.

Tobita, T., Sawada, S. 2006. Rotation Response of a Rigid Body under Seismic Excitation. J. Engineering. Mech., 132:375-84

Zivanovic, S., Pavic, A., Reynolds, P. 2006. Modal testing and FE model tuning of a lively footbridge structure. Engineering Structures; 28:857-68. 
Table 1. Comparison of the dimensions of different Gothic cathedrals (Salas, 2002).

\begin{tabular}{|c|c|c|c|c|c|c|}
\hline \multirow[t]{2}{*}{ Cathedral } & \multicolumn{2}{|c|}{ Main nave } & \multicolumn{2}{|c|}{ Aisle } & \multicolumn{2}{|c|}{ Pillars } \\
\hline & Span (m) & Height(m) & Span (m) & Height (m) & Side/span & Height/side \\
\hline Mallorca & 17.8 & 43.95 & 8.75 & 29.4 & 0.08 & 15 \\
\hline Girona & 21.8 & 34.2 & \multicolumn{2}{|c|}{ One aisle } & \multicolumn{2}{|c|}{ None } \\
\hline Milano & 16.4 & 44 & 7 & 29 & 0.17 & 9 \\
\hline Beauvais & 13.4 & 46.3 & 5 & 21 & 0.16 & 7.1 \\
\hline Amiens & 12.4 & 41.5 & 6.4 & 18.7 & 0.14 & 7.5 \\
\hline Reims & 12 & 36.4 & 5.3 & 16 & 0.15 & 5 \\
\hline Paris & 11.85 & 31.4 & 4.6 & 10.2 & 0.11 & 4.5 \\
\hline Salamanca & 11 & 34 & 7.3 & 22.4 & 0.25 & 3.5 \\
\hline Barcelona & 11 & 25.6 & 5.5 & 20.5 & 0.16 & 8.5 \\
\hline
\end{tabular}


Table 2. Initial (left) and final (right) parameters for the analysis of eigenvalues.

\begin{tabular}{cccccc}
\hline Structural & Young & Density & Poisson & Compressive & Tensile \\
member & Modulus & $\left(\mathrm{kg} / \mathrm{m}^{3}\right)$ & Modulus & Strength & Strength \\
& (MPa) & & & $(\mathrm{MPa})$ & (MPa) \\
\hline Pillars and & $8000 / 15264$ & 2400 & 0.2 & 8 & 0.4 \\
flying arches & & & & & 0.1 \\
Vaults, walls & $2000 / 3816$ & 2100 & 0.2 & 2 & 0.1 \\
Buttresses & $2000 / 3600$ & 2100 & 0.2 & 2 & 0.05 \\
Vault Fillings & $1000 / 1908$ & 2100 & 0.2 & 1 & \\
\hline
\end{tabular}


Table 3. Frequencies measured experimentally and from the analytical model calibrated.

\begin{tabular}{ccc}
\hline & $\begin{array}{c}\text { Experimental Frequency } \\
(\mathrm{Hz})\end{array}$ & $\begin{array}{c}\text { Analytical Model } \\
\text { Calibrated Frequency (Hz) }\end{array}$ \\
Vibration Modes & 1.28 & 1.28 \\
\hline 2 & 1.47 & 1.60 \\
\hline 3 & 1.59 & 1.70 \\
\hline 5 & & 1.86 \\
\hline & 1.84 & 1.93 \\
\hline
\end{tabular}


FIGURES

Figure 1. Exterior of the Mallorca cathedral. Author: G. Martínez.



Figure 2. Picture of the flying arches with one being supported by a masonry column. Author: G. Martínez.

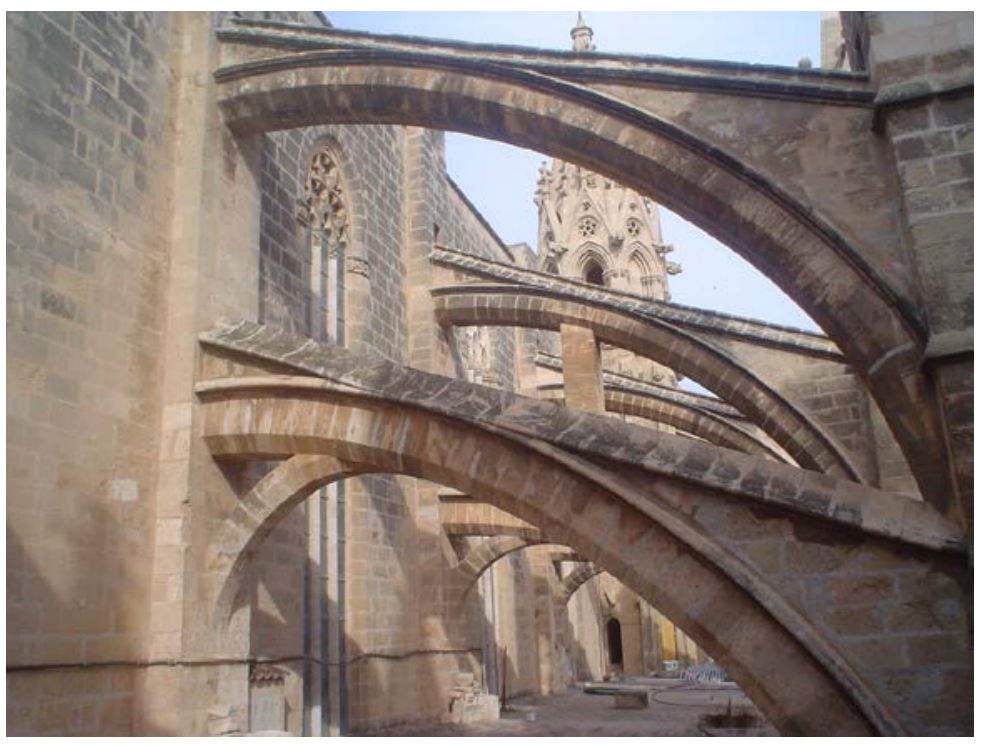


Figure 3. Picture of the dead weight located on top of one of the main nave arches. A seismograph is placed right next to it. Author: G. Martínez.

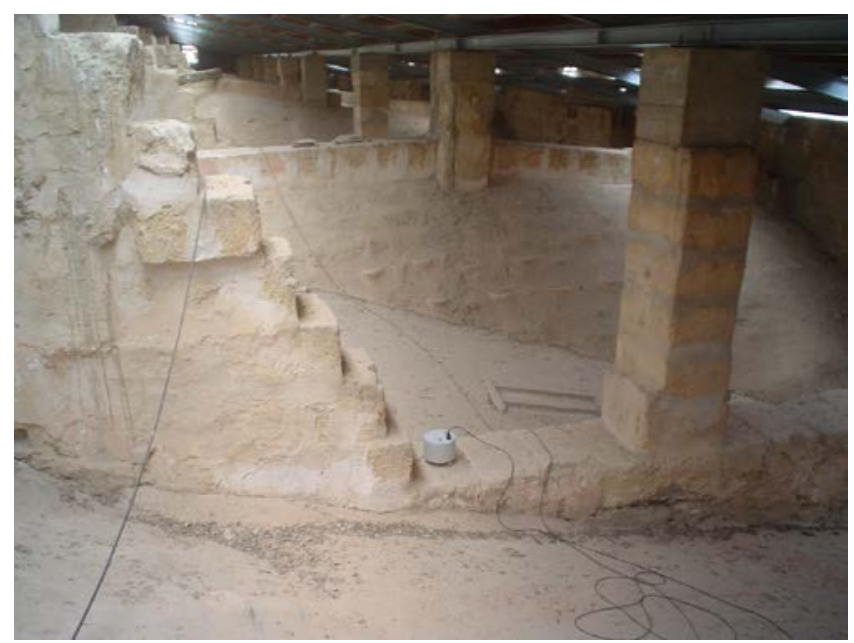

Figure 4. Plane view of Mallorca Cathedral with the location of the vibration measuring points.

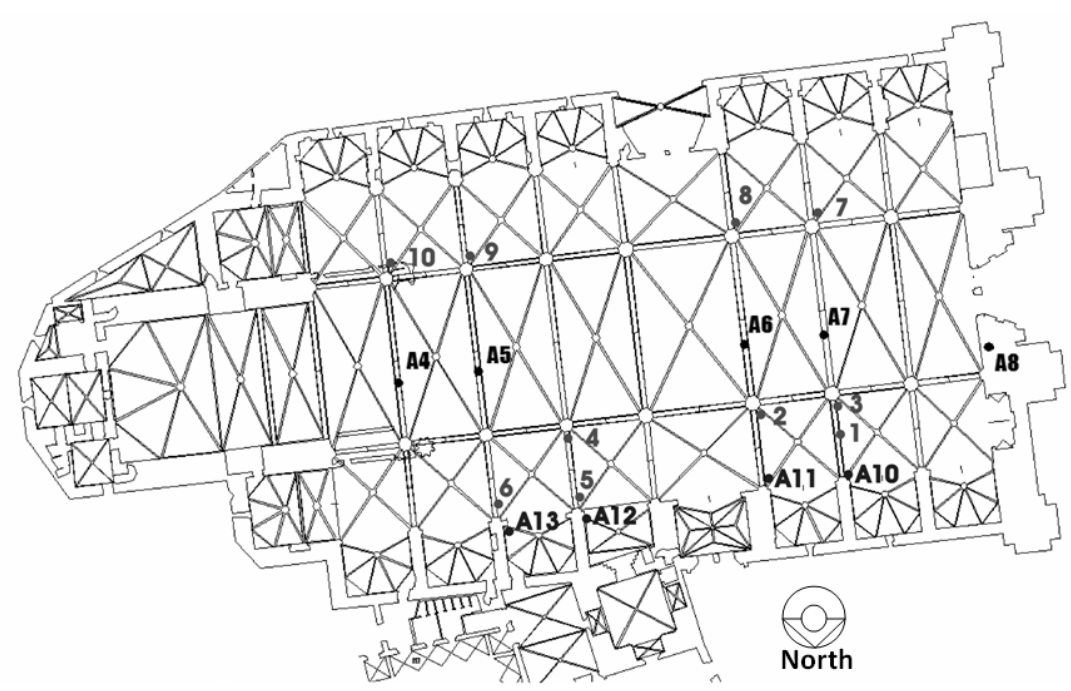




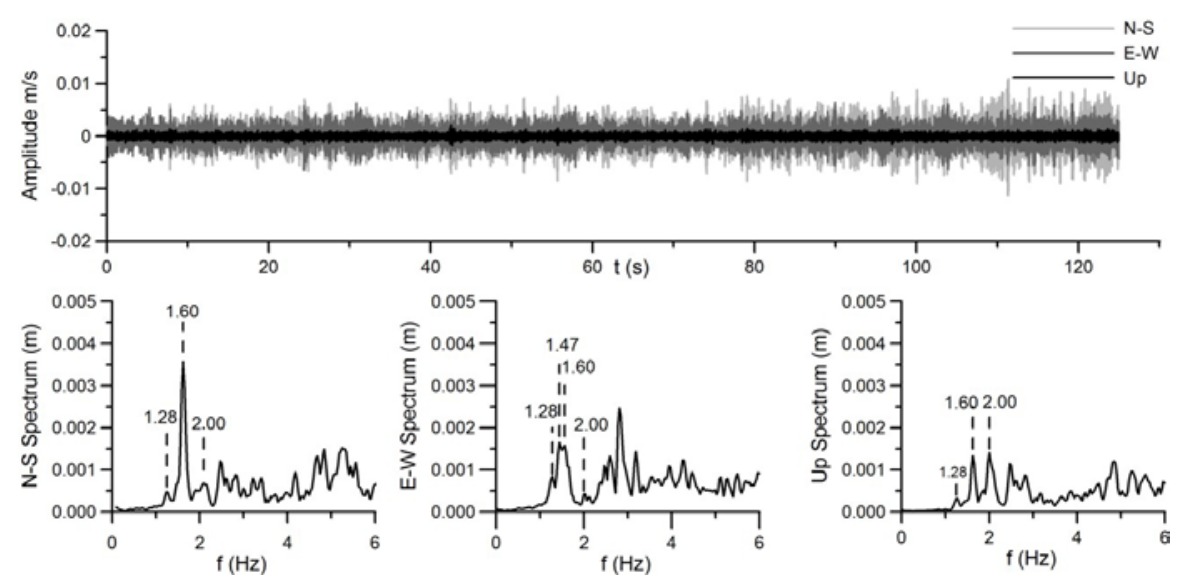

Figure 6. Time signal, spectra and signal projections at Point A5 (Figure 4) filtered for the frequencies of the first vibration mode $(1.28 \mathrm{~Hz})$.
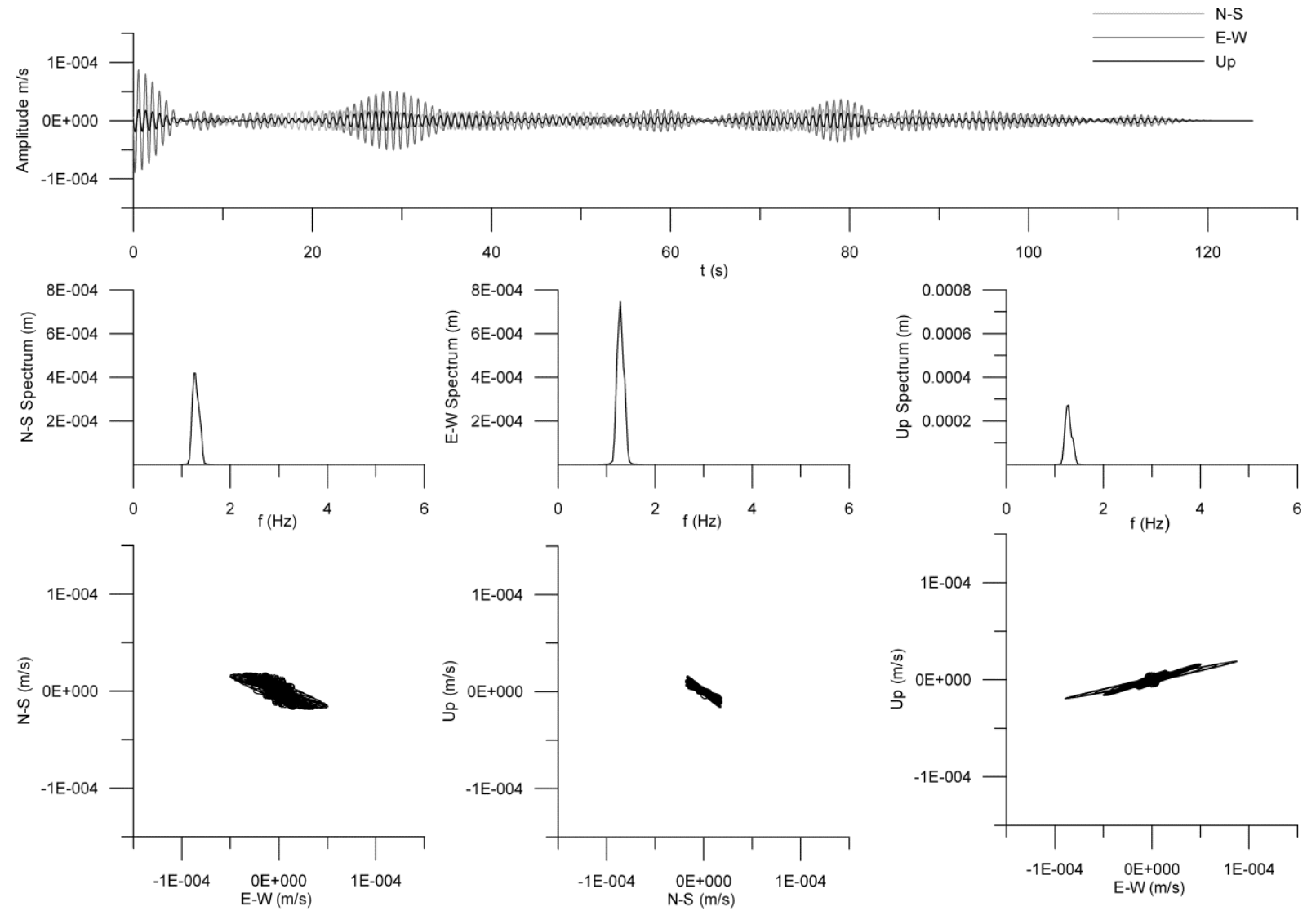
Figure 7. Finite element 3D mesh generated for the global model.
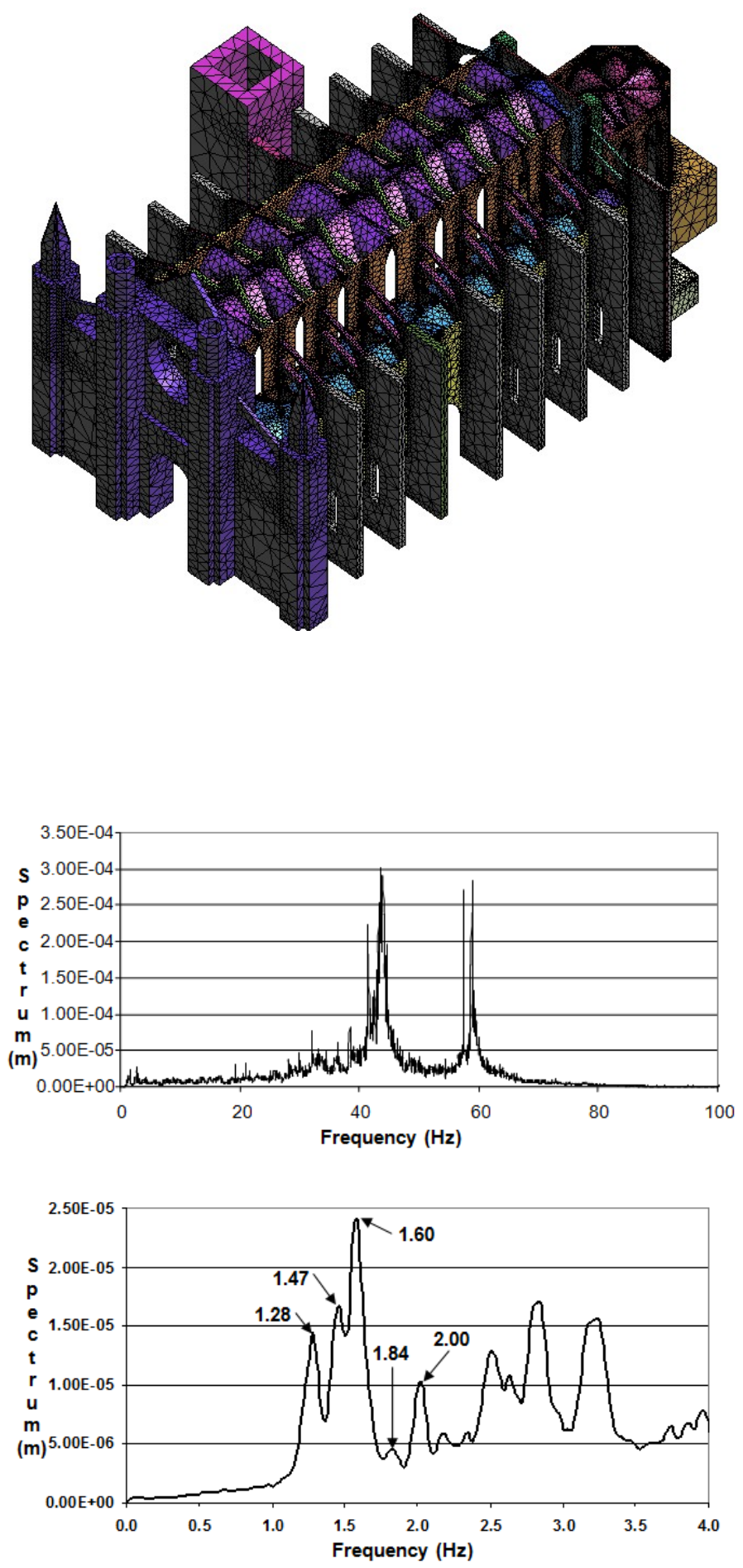
Figure 9. Particle horizontal movements of the five first vibration modes at Points A4, A5, A7 and A8.

A4)
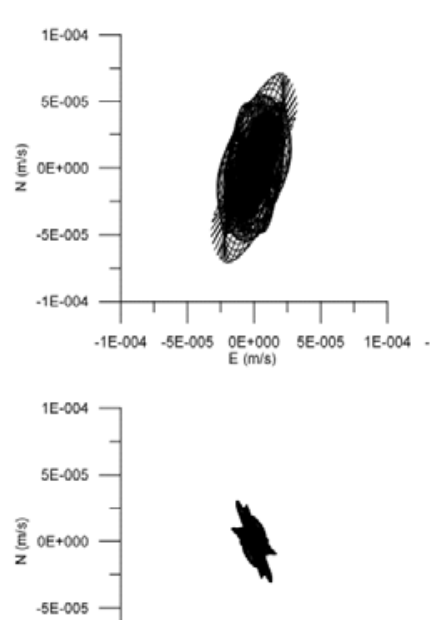

-5E-005

$-1 E-004$

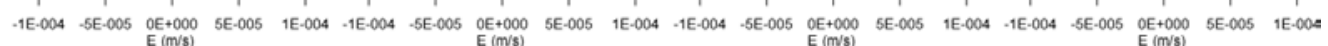
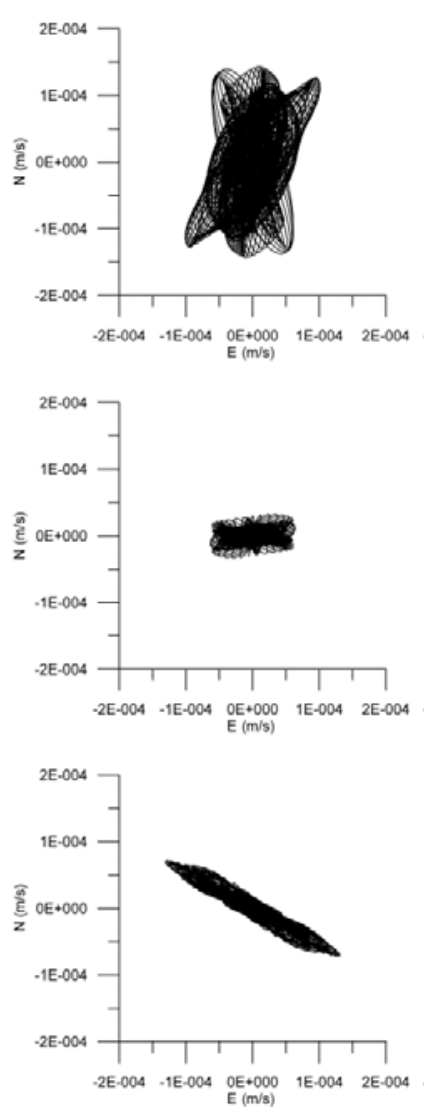

A5)


A7)
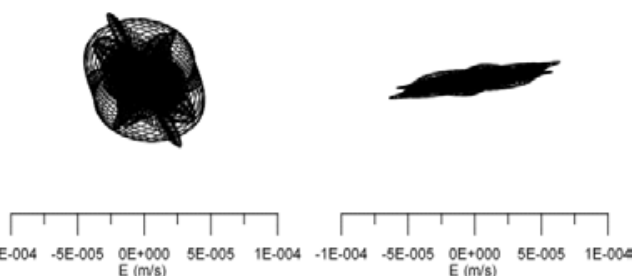

4th Mode

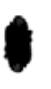

3rd Mode
A8)
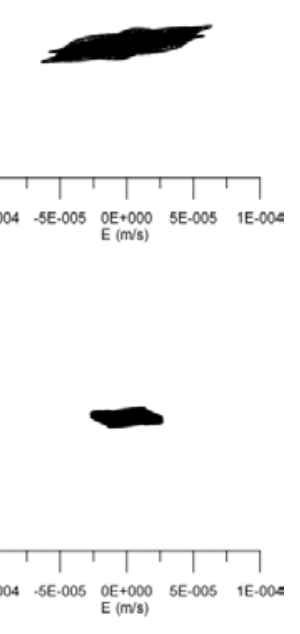
Figure 10. Particle vertical movements of the five first vibration modes at Points A4, A5, A7 and A8.
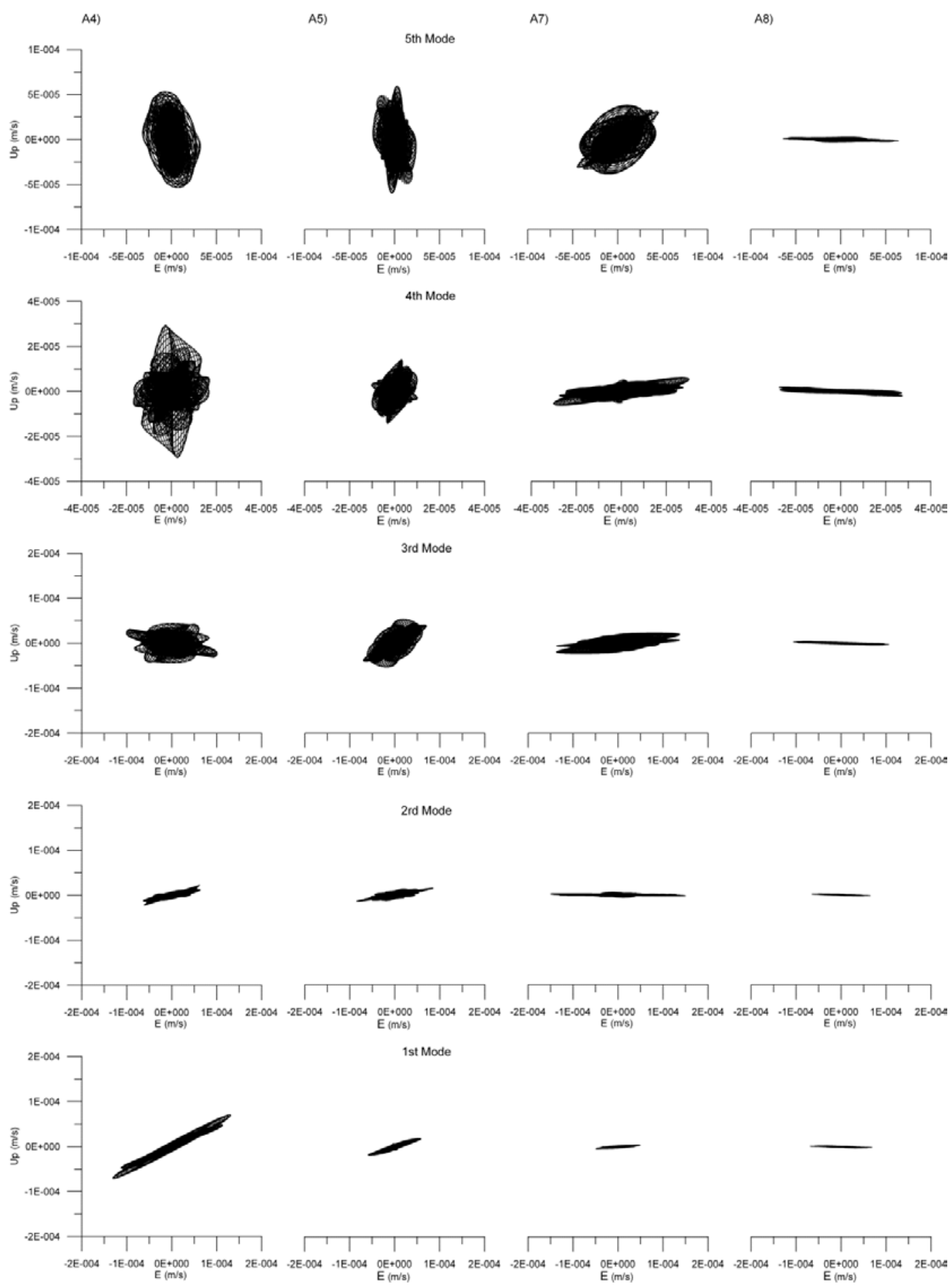
Figure 11. Particle horizontal movements of the five first vibration modes at Points 6, A5 and 9.

6)



8E-005 7 4th Mode
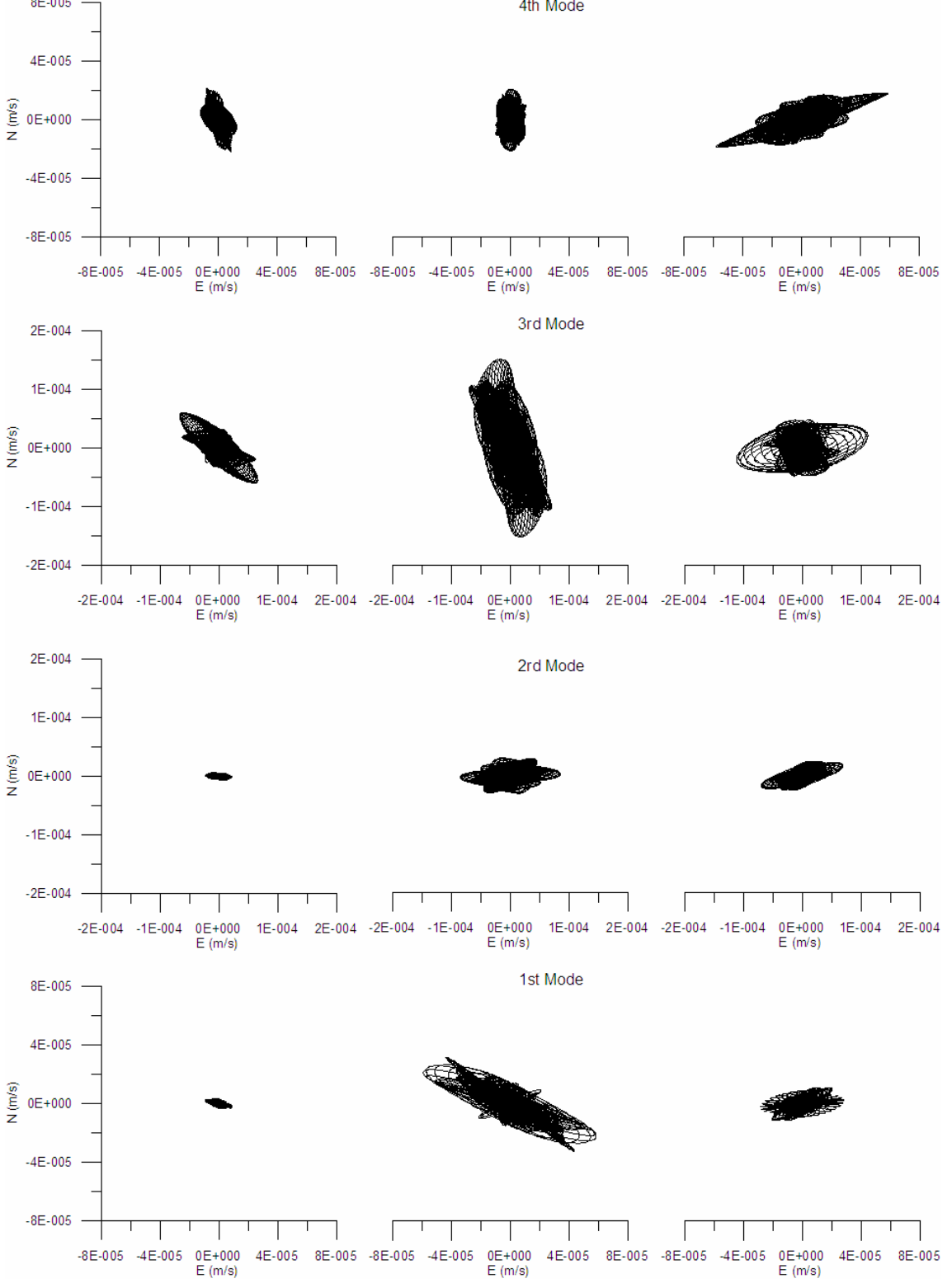
Figure 12. Images captured from the numerical animation of the first vibration mode at Point A8.



Figure 13. Comparison of the experimental and numerical modal shape of the first vibration mode at Point A8.
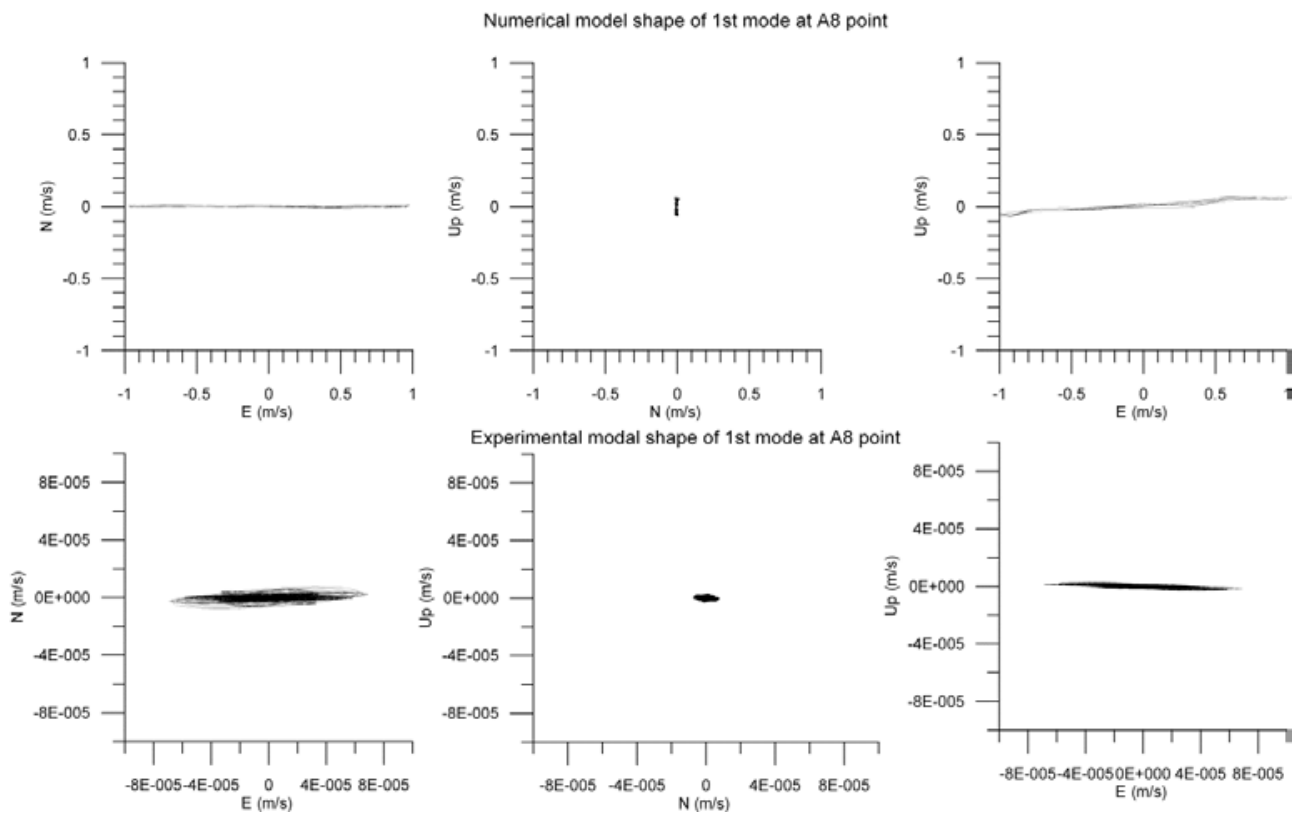
Figure 14. Comparison of the experimental and numerical modal shape of vibration mode 3 at Point A4.
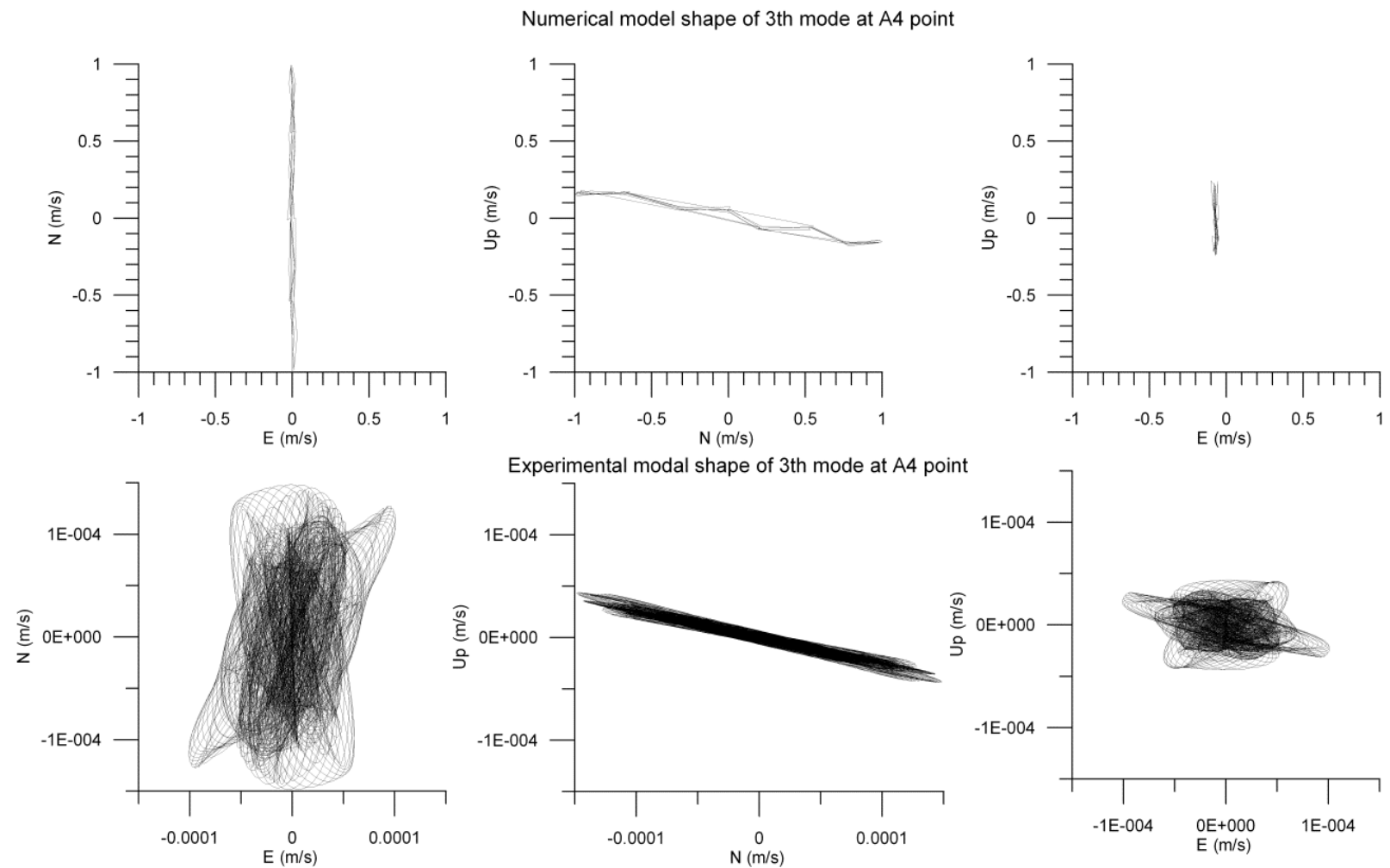